\title{
Nodular primary localized cutaneous amyloidosis: presentation of 2 case reports and literature review
}

\author{
Cláudia Rosado ${ }^{1}$, Clarinda Neves ${ }^{1}$, Raquel Cruz ${ }^{1}$, Manuela Loureiro² \\ ${ }^{1}$ Serviço de Medicina Interna. Centro Hospitalar do Baixo Vouga (CHBV) E.P.E. Aveiro. Portugal \\ ${ }^{2}$ Serviço de Dermatologia. Centro Hospitalar do Baixo Vouga (CHBV) E.P.E. Aveiro. Portugal
}

\begin{abstract}
The nodular primary localized cutaneous amyloidosis is rare and characterized by skin deposition of amyloid substance. There are cases of progression to invasive disease. The type of amyloid substance is not specific to this disease, also being found in primary systemic amyloidosis or systemic amyloidosis associated with multiple myeloma.

The authors describe two cases of nodular primary localized cutaneous amyloidosis. A 70-year-old man underwent excision of papule on the mouth left commissure, and a 39-year-old woman with a vulva's labia majora swelling that was excised, in which the histology revealed a nodular amyloidosis, both without systemic involvement.

Although the prognosis is benign, the follow-up of the patient is required for early detection of a possible evolution to systemic disease, or exclusion of an underlying systemic amyloidosis.
\end{abstract}

Key words: Primary cutaneous amyloidosis. Amyloidosis. Amyloid substance Palabras clave: Amiloidosis cutánea primaria. Amiloidosis. Sustancia amiloide.

\section{Introduction}

Amyloidosis is a common term used to describe a collection of diseases that are characterized by extracellular deposition of insoluble fibrillar protein amyloid substance. ${ }^{1,2,3,4,5}$ It can be divided into systemic and localized forms. ${ }^{1,2,4,5}$ In the former, there is widespread deposition of amyloid substance in various organs and tissues, while in the latter the deposition of this material is restricted to a single organ or tissue. ${ }^{2}$ Both can be further subdivided into primary or secondary. ${ }^{1}$

The primary localized cutaneous amyloidosis is a rare disorder characterized by three clinically and histologically distinct variants: macular, lichenoid and nodular, the last variant being the rarest. ${ }^{6,7}$ The type of amyloid substance found in this variant is not unique to the localized form, being also found in primary systemic amyloidosis or amyloidosis associated with multiple myeloma. ${ }^{8}$ The risk of progression for the systemic amyloidosis ranges from 7 to $50 \%$. $1,3,5,6,8$

In this work, we present two cases of nodular localized cutaneous amyloidosis.

\section{Case 1}

70-year-old Caucasian man, with hypertension, type 2 diabetes and hypercholesterolemia, with a 2-year history of a non pruriginous erythematous papule on left commissure of his mouth (Figure 1). The patient had no other systemic complaints. The skin lesion biopsy showed amorphous eosinophilic material in the dermis, with a tendency to confluence and positivity for the Congo Red staining, compatible with histological diagnosis of nodular amyloidosis (Figure 2). A total excision of the lesion was conducted, to exclude systemic disease. Laboratory testing showed normal complete blood count, erythro- cyte sedimentation rate, C-reactive protein, renal and liver function, serum and urine protein electrophoresis, immunoglobulins, serum and urine light chains, 32 -microglobulin and 24-hour urine protein. In addition, antinuclear antibodies and serology for syphilis, human immunodeficiency virus and hepatitis $B$ and $C$ virus, were all negative. A chest $X$-ray, abdominal ultrasound and electrocardiogram were normal. An echocardiogram showed normal left ventricular systolic function, left atrium slightly enlarged and left ventricular diastolic dysfunction.

One year after the excision, a new papular lesion on left commissure of his mouth appeared, and it was excised. Histology revealed a recurrence of nodular amyloidosis.

Currently, the patient remains in follow-up, with no evidence of systemic disease.

\section{Case 2}

39-year-old woman, with asthma and hypertension, was assessed due to hyper-pigmented swelling of her vulva labia majora, which had appeared since one year before. She referred painful bouts. Excision of this vulva lesion was performed, and histological examination showed nodular deposits of amorphous eosinophilic material in the dermis, without signs of malignancy. Staining with Congo Red was positive for amyloid substance. Other skin lesions and systemic disease were searched and excluded.

Laboratory testing included complete blood count, erythrocyte sedimentation rate, C-reactive protein and coagulation study, which were all normal; kidney and liver function were unremarkable, as well as angiotensin converting enzyme, serum protein electrophoresis, immunoglobulins, light chains, $\beta 2$-microglobulin and antinuclear antibodies. Serology for syphilis, human immunodeficiency virus and hepatitis $C$ virus were negative, and the patient was immune to hepatitis B. Normal 24-hour urine protein. An abdominal computed tomography (CT) scan, electrocardiogram and echocardiogram were normal. A biopsy of periumbilical subcutaneous tissue did not reveal histopathologic findings suggested of amyloid substance. Currently, the patient remains in follow-up, with no evidence of systemic disease.

\section{Discussion}

The localized cutaneous amyloidosis is a rare type of amyloidosis in which extracellular amyloid substance deposits are located only in the skin, and includes three variants: lichenoid, macular and nodular amyloidosis. ${ }^{6,8,9,10}$

The lichenoid and the macular amyloidosis are often grouped together, since both have constituents derived from keratin on amyloid deposits, that do not invade the blood vessels and do not extend below the papillary dermis. ${ }^{6,8}$

The nodular amyloidosis is the rarest variant, 5,6,8,9 its amyloid deposits are formed by immunoglobulin light chains (AL amyloid 
Figure 1. Photograph of the papular lesion located at the left corner of the mouth.

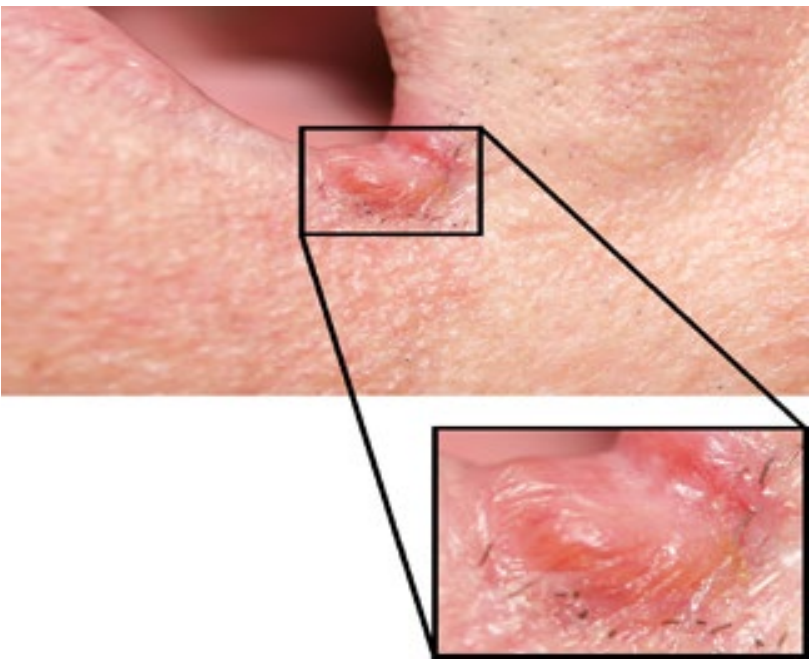

substance type $)^{6,8,9}$ produced by local plasma cells, 6,11 infiltrating the entire dermis, the subcutaneous layer and the blood vessel wall. 6,8 The AL protein is not specific for the nodular cutaneous amyloidosis, it also exists in the primary systemic amyloidosis or the amyloidosis associated with multiple myeloma.

There are reports of nodular cutaneous amyloidosis associated with systemic diseases like diabetes, ${ }^{4}$ and autoimmune diseases, such as Sjögren's syndrome, 2,8,12 CREST syndrome, primary biliary cirrhosis, rheumatoid arthritis and systemic lupus erythematosus. ${ }^{5,6,13}$ Other rare associations described in the literature include alcoholic cirrhosis, ${ }^{11}$ atopic dermatitis ${ }^{14,15}$ and sarcoidosis ${ }^{7}$. In one of the case reports presented here the patient was diabetic.

The nodular localized cutaneous amyloidosis may manifest itself as a pinkish, or brownish, single or multiple nodes or plates, which appear most frequently in the legs, followed by the head, trunk, arms and genitals. ${ }^{5}$ The disease is most prevalent between the 4th and 6th decades of life without gender predominance. $3,4,5$

There are reports of progression from nodular cutaneous amyloidosis to primary systemic amyloidosis. ${ }^{6}$ The risk of progression varies from 7 to $50 \%{ }^{1,3,5,6,8}$ Consequently, it is important to exclude underlying systemic disease and longterm clinical monitoring is recommended. There are no formal guidelines to monitor these patients. ${ }^{6}$ Searching for possible systemic disease is advisable and it should include: complete blood count, serum and urine protein electrophoresis, antinuclear antibodies, renal and liver function tests, 24-hour urine protein, chest radiograph, electrocardiogram, abdominal ultrasound and echocardiogram. An abdominal wall fat biopsy with Congo Red staining may also be performed. ${ }^{6}$ The radiolabelled serum amyloid $\mathrm{P}$ component scintigraphy allows multiple organ detection of amyloid deposits in vivo. ${ }^{5}$ In our case reports there is no current evidence of systemic disease.

There are many treatments recommended for nodular cutaneous amyloidosis (cryotherapy, dermabrasion, laser therapy and surgical excision). However, none of them proved to be consistently effective, and recurrence is frequent, ${ }^{5,6}$ which

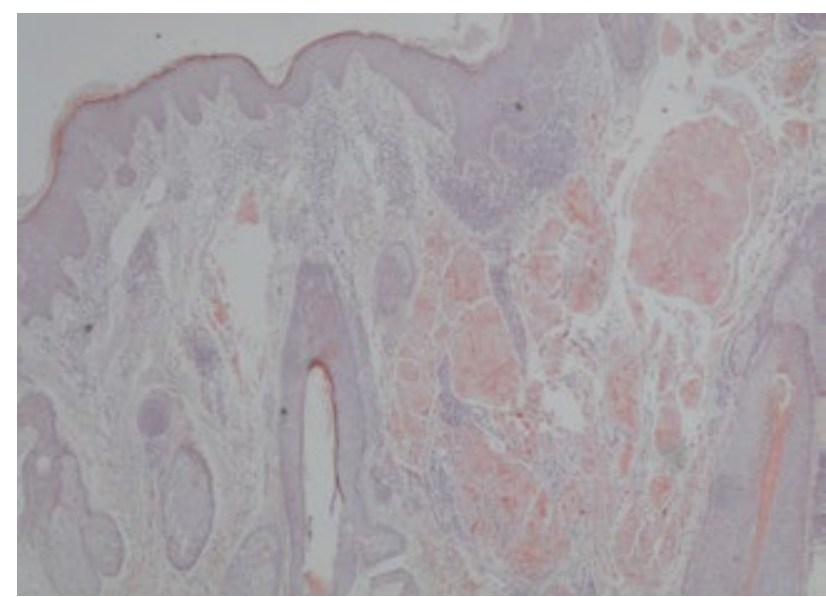

happened in one of the case reports presented here, one year after the complete surgical excision of the lesion.

Nodular primary localized cutaneous amyloidosis is a rare disease that can cause aesthetic and functional changes that lead patients to seek treatment, but with a benign prognosis. However, understanding how to properly diagnose and treat this condition, as well as the need for surveillance and monitoring of the patient for early detection of a possible evolution to systemic disease, or the exclusion of an underlying systemic amyloidosis, are critical in patient's prognosis.

\section{References}

1. Terushkin V, Boyd KP, Patel RR, McLellan B. Primary localized cutaneous amyloidosis. Dermatol Online J. 2013 Dec 16;19(12):20711.

2. Meijer JM, Schonland SO, Palladini G, Merlini G, Hegenbart U, Ciocca O, et al. Sjögren's Syndrome and Localized Nodular Cutaneous Amyloidosis: Coincidence or a Distinct Clinical Entity? Arthritis Rheum. 2008 Jul;58(7):1992-9. doi: 10.1002/art.23617.

3. Kaltoft B, Schmidt G, Lauritzen AF, Gimsing P. Primary localized cutaneous amyloidosis systematic review. Dan Med J. 2013 Nov;60(11):A4727.

4. Souza Júnior Jd, Schettini RA, Tupinambá WL, Schettini AP, Chirano CA, Massone C. Amiloidose localizada cutânea primária nodular - Relato de caso. An Bras Dermatol. 2011 Sep-0ct;86(5):987-90.

5. Luo S, Cha J, Wilkel C, Breen C, Zhou LH. The Diagnosis: Primary Localized Cutaneous Nodular Amyloidosis. Cutis. 2013 Jun;91(6):271, 283-4.

6. Ritchie SA, Beachkofsky T, Schreml S, Gaspari A, Hivnor CM. Primary Localized Cutaneous Nodular Amyloidosis of the Feet: A Case Report and Review of the Literature. Cutis. 2014 Feb;93(2):89-94.

7. Nakai N, Ozawa A, Katoh N. Nodular Primary Localized Cutaneous Amyloidosis in a Patient with Pulmonary Sarcoidosis. Indian J Dermatol. 2014 May;59(3):307-8. doi: 10.4103/0019-5154.131430.

8. Konopinski JC, Seyfer SJ, Robbins KL, Hsu S. A case of nodular cutaneous amyloidosis and review of the literature. Dermatol Online J. 2013 Apr 15;19(4):10.

9. Villar M, Burgués M, Rodríguez-Peralto JL, Rivera R, Vanaclocha F. Localized Primary Cutaneous Nodular Amyloidosis in a Patient With Paraproteinemia. Actas Dermosifiliogr. 2012 Mar;103(2):161-2. doi: 10.1016/j.ad.2011.05.017. Epub 2011 Aug 31.

10. Suranagi VV, Siddramappa B, Bannur HB, Patil PV, Davangeri RS. Bullous Variant of Familial Biphasic Lichen Amyloidosis: A Unique Combination of Three Rare Presentations. Indian J Dermatol. 2015 Jan-Feb;60(1):105. doi: 10.4103/0019-5154.147868.

11. Ueno $M$, Yamamoto $T$, Yamanaka $M$, Matsunaga $T$. Nodular amyloidosis in a patient with liver cirrhosis. Dermatol Online J. 2011 Jul 15;17(7):10.

12. Brown AJ, Spicknall KE, Mutasim DF. Multiple lesions of primary cutaneous nodular amyloidosis in Sjögren syndrome. J Am Acad Dermatol. 2012 Dec;67(6):e267-8. doi: 10.1016/j. jaad.2012.05.012.

13. Summers EM, Kendrick CG. Primary Localized Cutaneous Nodular Amyloidosis and CREST Syndrome: A Case Report and Review of the Literature. Cutis. 2008 Jul;82(1):55-9.

14. Chia B, Tan A, Tey HL. Primary localized cutaneous amyloidosis: association with atopic dermatitis. J Eur Acad Dermatol Venereol. 2014 Jun;28(6):810-3. doi: 10.1111/ jdv.12144. Epub 2013 Mar 12.

15. Fujisawa T, Shu E, Ikeda T, Seishima M. Primary localized cutaneous nodular amyloidosis that appeared in a patient with severe atopic dermatitis. J Dermatol. 2012 Mar;39(3):3123. doi: 10.1111/j.1346-8138.2011.01247.x. Epub 2011 Jul 18. 